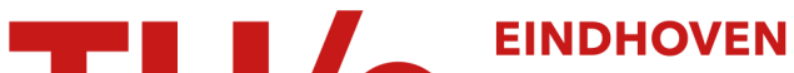 \\ UNIVERSITY OF \\ TECHNOLOGY
}

\section{High-speed optical signal processing for telecom applications}

\section{Citation for published version (APA):}

Liu, Y., Zhang, S., Liu, Y., Gomez-Agis, F., Tangdiongga, E., \& Dorren, H. J. S. (2010). High-speed optical signal processing for telecom applications. In Wireless and Optical Communications Conference (WOCC), 2010 19th Annual, Changhai, 14-15-10-2010 (pp. 1-5). Institute of Electrical and Electronics Engineers. https://doi.org/10.1109/WOCC.2010.5510682

DOI:

10.1109/WOCC.2010.5510682

Document status and date:

Published: 01/01/2010

\section{Document Version:}

Publisher's PDF, also known as Version of Record (includes final page, issue and volume numbers)

\section{Please check the document version of this publication:}

- A submitted manuscript is the version of the article upon submission and before peer-review. There can be important differences between the submitted version and the official published version of record. People interested in the research are advised to contact the author for the final version of the publication, or visit the $\mathrm{DOI}$ to the publisher's website.

- The final author version and the galley proof are versions of the publication after peer review.

- The final published version features the final layout of the paper including the volume, issue and page numbers.

Link to publication

\section{General rights}

Copyright and moral rights for the publications made accessible in the public portal are retained by the authors and/or other copyright owners and it is a condition of accessing publications that users recognise and abide by the legal requirements associated with these rights.

- Users may download and print one copy of any publication from the public portal for the purpose of private study or research.

- You may not further distribute the material or use it for any profit-making activity or commercial gain

- You may freely distribute the URL identifying the publication in the public portal.

If the publication is distributed under the terms of Article $25 f a$ of the Dutch Copyright Act, indicated by the "Taverne" license above, please follow below link for the End User Agreement:

www.tue.nl/taverne

Take down policy

If you believe that this document breaches copyright please contact us at:

openaccess@tue.nl

providing details and we will investigate your claim. 


\section{High-Speed Optical Signal Processing for Telecom Applications}

\author{
Yong Liu, Shangjian Zhang, and Yongzhi Liu \\ School of Optoelectronic Information \\ University of Electronic Science and Technology of China \\ Chengdu, China, 610054 \\ YongLiu@uestc.edu.cn
}

\author{
F. Gomez-Agis, E. Tangdiongga, and H. J. S. Dorren \\ COBRA Research Institute \\ Eindhoven University of Technology, P.O. Box 513 \\ NL-5600 Eindhoven, The Netherlands
}

\begin{abstract}
We discuss high-speed optical signal processing for telecom applications. We focus on the optical wavelength conversion and self-clocking, respectively. In the optical wavelength conversion, we report $40 \mathrm{~Gb} / \mathrm{s}$ wavelength conversion that is capable of converting the same wavelength using a single semiconductor optical amplifier. Experimental proofs are presented. In addition, we report a novel self-clocking method based on in-band clock pilot insertion at the transmission data signal. The method provides clock recovery without an ultrafast phase comparator and a phase-locked loop in the receiver. Fast synchronization, low timing jitter and a highly stable recovered clock is demonstrated from $160 \mathrm{~Gb} / \mathrm{s}$ OTDM data signal after 51km fiber transmission.
\end{abstract}

Keywords-optical signal processing, optical wavelength conversion, seminconductor optical amplifier, optical clock recovery, optical time-division multiplexing

\section{INTRODUCTION}

Optical signal processing is receiving considerable attention since it can play an important role in reducing footprint and power consumption of high-speed optical networks [1].Optical wavelength conversion and clock recovery are two important topics in the field of optical signal processing.

In the semiconductor-based wavelength conversion approaches, error-free $320 \mathrm{~Gb} / \mathrm{s}$ wavelength conversion has been achieved by using semiconductor optical amplifiers (SOAs) with co-propagation scheme [2], In the system application, it is desirable for the wavelength converter to have the capability to convert any input wavelength to any output wavelength. This requires the wavelength converter has the capability of converting the information to the same wavelength. Currently, most wavelength converters utilize copropagation scheme that can achieve high operating speed [2$6]$, but can not convert the same wavelength directly. In the copropagation scheme, an optical filter is used to block the pump data signal and allow the converted probe light to pass through. To convert the information to the same wavelength, one needs firstly convert the pump data signal to a different wavelength, and then convert it back to the original input wavelength. Therefore, two wavelength converters are required [7].

Clock recovery is essential for a receiver to synchronize to a transmitted data signal in an optical communication system. In an optical time-division multiplexing (OTDM) network, the clock should be recovered at the base-rate for the requirement of optical demultiplexing and time-division add-drop multiplexing. The typical way for clock recovery is injectionlocked optical phase comparison between the received OTDM signal and the locally generated clock signal. Non-linearities such as four-wave mixing [8] or cross-phase modulation in SOAs [9] or nonlinear fibers [10], three wave-mixing in periodically-poled lithium niobate (PPLN) waveguides [11] or electro-absorption modulation (EAM) [12], have been exploited to provide the phase comparator functionality. Nevertheless, when ultra-high speed operation $(\geqslant 160 \mathrm{~Gb} / \mathrm{s})$ is involved, the major difficulty for the phase comparator lies in the very high time-resolution required because of the short duration of the bit time-slot. Also, often in the phase-locked loop (PLL) scheme, the locking time works inversely with the timing jitter: shorter locking time means larger timing jitter [11]. So, clock recovery methods which are capable of reducing the locking-time and at the same time keeping the timing jitter low are of great interest.

In this paper, we firstly demonstrate $40 \mathrm{~Gb} / \mathrm{s}$ wavelength conversion that is capable of converting the same wavelength using a single SOA in a counter-propagation scheme. Errorfree operation is achieved. Secondly, we report a self-clocking method that allows for fast synchronization, low timing jitter and highly stable clock performance for time-demultiplexing functions. The method consists of inserting a $10 \mathrm{GHz}$ clock pilot signal at the transmitter, and extracting this pilot signal at the receiver. The wavelength of the pilot signal is within the $20 \mathrm{~dB}$ bandwidth of the data signal. The base-rate clock signal is recovered by spectrally separating the pilot from the data, photodetecting, and quadrupling $(\times 4)$ the pilot signal to 40 $\mathrm{GHz}$. This method eliminates the use of an ultrafast phase comparator and a PLL in the receiver. Error-free operation from 160-to-40 $\mathrm{Gb} / \mathrm{s}$ demultiplexing after $51 \mathrm{~km}$ of fiber transmission with a power penalty of $1.1 \mathrm{~dB}$ is demonstrated.

\section{II. $40 \mathrm{~GB} / \mathrm{S}$ WAVELENGTH CONVERSION CONVERTING THE SAME WAVELENGTH}

The experimental setup of all-optical wavelength conversion (AOWC) is shown in Figure 1. The setup was constructed by using commercial available fiber-pigtailed components. A tunable laser emits a continuous wave $(\mathrm{CW})$ probe beam at wavelength $\lambda_{\text {probe }}$ that is fed into an SOA via an

This work was supported by the Chinese NSFC program (No. 60925019 , 60907008), NCET program (No. NCET-07-0152). The work was also partially supported by the Netherlands Science Foundation (NWO) and the Netherlands Technology Foundation (STW) through the NRC Photonics and Vi programs. 


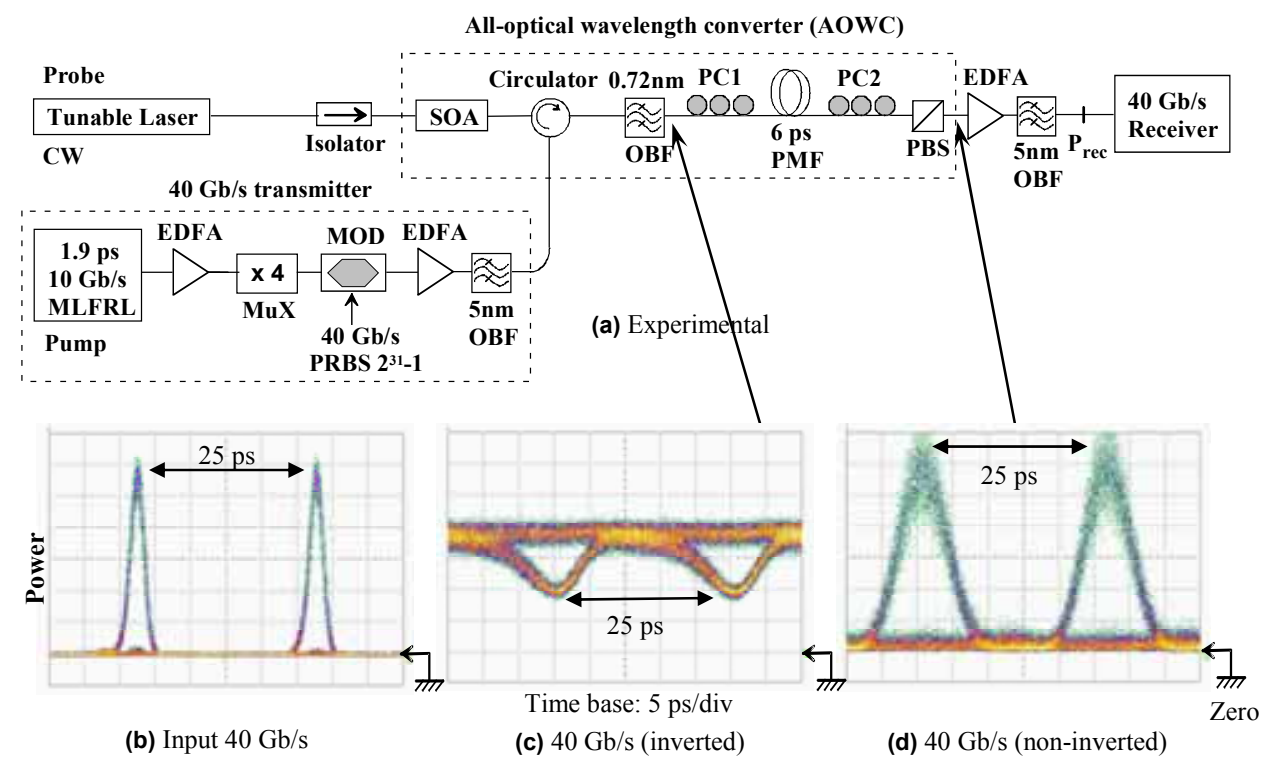

Figure 1. (a) $40 \mathrm{~Gb} / \mathrm{s}$ all-optical wavelength conversion setup. (b) eye-diagram of the $40 \mathrm{~Gb} / \mathrm{s}$ input pump signal. (c) and (d) are eye-diagrams at various positions in the all-optical wavelength converter. The eye diagrams are measured by a 700-GHz optical sampling scope. X: pulse interleaver,

optical isolator. A $10 \mathrm{~Gb} / \mathrm{s}$ optical clock signal with 1.9 ps-wide optical pulses, generated by an actively modelocked fiber ring laser, is amplified and is subsequently sent into an optical multiplexer, where passive fiber-based pulse interleavers are used to multiplex the $10 \mathrm{~Gb} / \mathrm{s}$ optical clock to $40 \mathrm{~Gb} / \mathrm{s}$. The $40 \mathrm{~Gb} / \mathrm{s}$ optical clock is subsequently modulated by an external modulator at $40 \mathrm{~Gb} / \mathrm{s}$ to form a $2^{31}-1$ return-to-zero (RZ) pseudo random binary sequence (PRBS). This $40 \mathrm{~Gb} / \mathrm{s}$ RZ-PRBS data signal is launched into the SOA via an optical circulator. The system has a counter-propagated configuration since the $\mathrm{CW}$ probe light and the $40 \mathrm{~Gb} / \mathrm{s}$ RZ-PRBS pump signal travel through the SOA with an opposite direction.

As shown in the dashed box in the Figure 1, the AOWC is made out of an SOA, a $0.72 \mathrm{~nm}$ optical bandpass filter (OBF) and a delayed-interferometer. The delayedinterferometer consists of two polarization controllers (PCs), a polarization maintaining fiber (PMF) with 6 ps differential delay, and a polarization beam splitter (PBS). In principle, the delayed-interferometer in Figure 4 can be replaced by an integrated version shown in [4]. The SOA in the AOWC is a commercial product from JDS Uniphase, having an active length of $800 \mu \mathrm{m}$ and employing a strained bulk active region. The SOA is pumped with $350 \mathrm{~mA}$. The center wavelengths of the $40 \mathrm{~Gb} / \mathrm{s}$ data signal is $1552.52 \mathrm{~nm}$. The wavelength of the $\mathrm{CW}$ probe beam is firstly set at 1552.52 $\mathrm{nm}$ (the same wavelength as the data signal) to test the performance of converting the same wavelength. Then the wavelength of the $\mathrm{CW}$ probe beam is changed to be 1560.63 $\mathrm{nm}$ to perform the function of converting the different wavelength. The optical power is measured at the input pigtail of the SOA. The average optical power of the 40 $\mathrm{Gb} / \mathrm{s}$ data stream is $-3.5 \mathrm{dBm}$ and $3 \mathrm{dBm}$ for $\mathrm{CW}$ probe light.
The injected $40 \mathrm{~Gb} / \mathrm{s}$ data signal modulates the SOA gain. As a result, the $\mathrm{CW}$ probe light is modulated via cross-gain modulation, causing inverted wavelength conversion. Moreover, the injected data signal also modulates the refractive index of the SOA, resulting in a chirped converted signal. The leading edges of the (inverted) converted probe light are red-shifted, whereas the trailing edges are blue-shifted. As a consequence, the spectrum of probe light at the SOA output is broadened. The $0.72 \mathrm{~nm}$ optical bandpass filter that is placed at the SOA output is $0.5 \mathrm{~nm}$ blue-detuned to select the blue-shifted sideband of the probe light, and shorten the recovery time of the SOA [3].

At the output of the $0.72 \mathrm{~nm}$ optical bandpass filter, the converted probe light is monitored by using an optical sampling scope with an optical measurement bandwidth up to $700 \mathrm{GHz}$. The result is presented in Fig. 4c. An inverted $40 \mathrm{~Gb} / \mathrm{s}$ signal with a clear open eye-pattern is obtained, which ensures the pattern-independence of $40 \mathrm{~Gb} / \mathrm{s}$ wavelength conversion. The inverted $40 \mathrm{~Gb} / \mathrm{s}$ converted signal is subsequently injected into the delayedinterferometer, where the polarity of converted signal is changed, i.e., inverted signal is changed into non-inverted signal. In addition, the slow gain saturation time is suppressed. The result is presented in Figure 1d.

After wavelength conversion, the converted signal is fed into a $40 \mathrm{~Gb} / \mathrm{s}$ receiver and a bit-error-rate (BER) tester. Fig. 2 shows BER measurements of the $40 \mathrm{~Gb} / \mathrm{s}$ input signal @1552.52nm and the converted signal (@1552.52nm and (a) $1560.63 \mathrm{~nm}$, respectively). It can be observed that the sensitivity penalty of the wavelength conversion at a $\mathrm{BER}=10^{-9}$ is about $3.5 \mathrm{~dB}$ for converting the same wavelength, and $2 \mathrm{~dB}$ for converting the different wavelength $(1552.52 \mathrm{~nm}$ to $1560.63 \mathrm{~nm})$. Moreover, it is visible that no error-floor is observed, which indicates excellent performance of the proposed wavelength 
conversion. The system has a larger penalty when the pump and probe light has the same wavelength. This is due to the reflected pump light at the SOA facet, which has the same wavelength as the probe light. The penalty can be improved by reducing the reflection from the SOA facet.

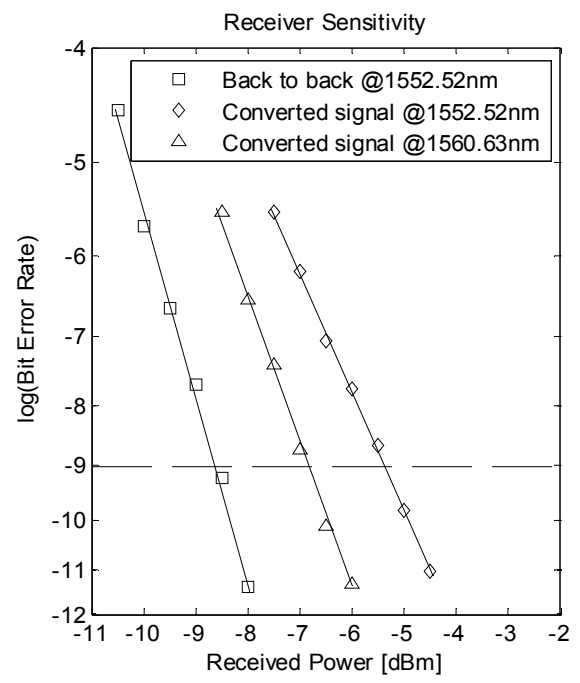

Figure 2. BER performance of $40 \mathrm{~Gb} / \mathrm{s}$ wavelength conversion

The inverted $40 \mathrm{~Gb} / \mathrm{s}$ eye-diagram presented in Figure 2c shows a slow gain saturation time and a fast recovery time, which is different from the co-propagation scheme shown in [2-3]. The fast recovery time is obtained because of the used blue-detuned optical filtering technology [3], which shortens the effective SOA-recovery time from 100 ps to less than 6 ps. This indicates that blue-detuned optical filtering technology still functions well in speeding up the recovery time of the counter-propagation system. In contrast to the ultra-fast gain saturation time in the co-propagation scheme [2-7], the counter-propagation scheme has a much more slow gain saturation time, which becomes a determinant factor for the operating speed of our scheme. The slow gain saturation time is caused by the active length of the SOA and the slow gain recovery time of the SOA. This long lived-tailed saturation time can be cancelled by using the delayed-interferometer, as shown in Figure 1d. This indicates higher operating speed $(>80 \mathrm{~Gb} / \mathrm{s})$ would be possible.

\section{SELF-CLOCKING FROM 160GB/S OTDM DATA SIGNAL}

The proposed self-clocking method is schematically shown in Figure 3. It consists of a $160 \mathrm{~Gb} / \mathrm{s}$ OTDM transmitter and receiver, connected by a dispersion-managed fiber span of 51 $\mathrm{km}$. In the transmitter, optical return-to-zero pulses generated by a fiber mode-locked laser (FMLL) with duration of $1.4 \mathrm{ps}$ at $1557 \mathrm{~nm}$ and $40 \mathrm{GHz}$ repetition rate (driven by a master clock), are optically gated to form an optical pseudo-random binary sequence (PRBS) signal. We characterize the clock and demultiplexing performance using three $40 \mathrm{~Gb} / \mathrm{s}$ PRBS patterns: $2^{7}-1,2^{15}-1$ and $2^{31}-1$. The $40 \mathrm{~Gb} / \mathrm{s}$ pulses are sent through fiber-based interleaver and time-multiplexed to constitute a $160 \mathrm{~Gb} / \mathrm{s}$ signal (shown in Figure 4(a)). Due to the fiber-based multiplexer, it is observed that the $160 \mathrm{~Gb} / \mathrm{s}$ signal is not phase-stable in the spectrum domain, so we determine the $160 \mathrm{GHz}$ peak lines from the stable spectrum of the $40 \mathrm{GHz}$ pulsed signal.

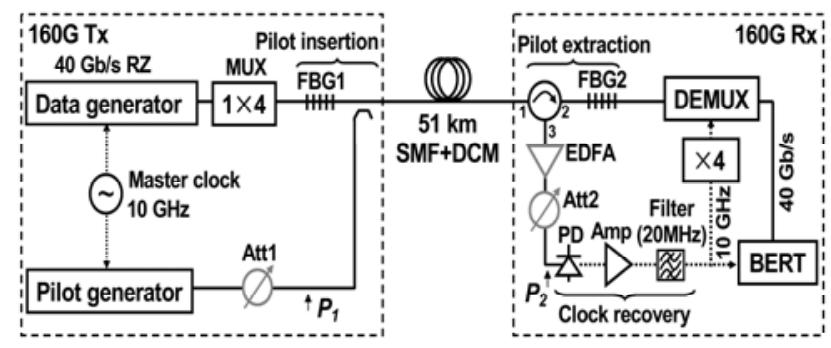

Figure 3. Experimental setup for self-clocking based on the in-band pilot method. MUX: Optical Time-domain Multiplexer, FBG: Fiber-Bragg Grating, Att: Attenuator, PD: Photodetector, Amp: Electrical Amplifier, DEMUX: Demultiplexer, EDFA: Erbium-Doped Fiber Amplifier, SMF: Single-mode Fiber, DCM: Dispersion Compensation Module.

The $160 \mathrm{~Gb} / \mathrm{s}$ data signal is then coupled into an optical fiber Bragg-grating (FBG1) with $0.4 \mathrm{~nm}$ bandwidth that carves a portion of the data spectrum where the pilot is going to be inserted. The central wavelength of the FBG1 is located at $1558.93 \mathrm{~nm}(\Delta \lambda=1.93 \mathrm{~nm}$ with respect to the data carrier), which is chosen to avoid crosstalk with the $160 \mathrm{GHz}$ spectral lines of the data signal in order to eliminate distortions and noise as much as possible. The pilot is generated by modulating a CW laser $(\lambda=1558.93 \mathrm{~nm})$ with the $10 \mathrm{GHz}$ master clock. The bias and driving power are optimized to suppress high-order harmonics and to keep a linear intensity modulation. Finally, the pilot is combined with the $160 \mathrm{~Gb} / \mathrm{s}$ data through an optical coupler.
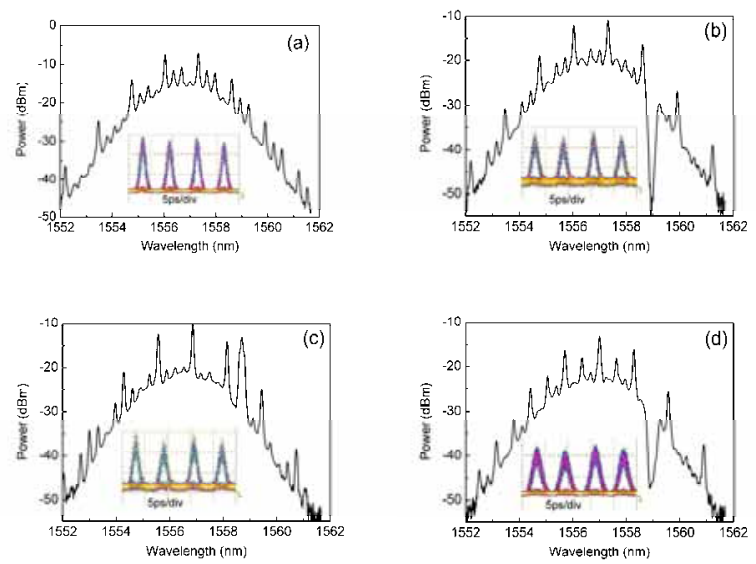

Figure 4. Spectra and waveforms of the $160 \mathrm{~Gb} / \mathrm{s}$ data signal. (a) Original signal, (b) Carved spectrum before pilot insertion, (c) In-band pilot insertion, (d) In-band pilot extraction.

The carved data-spectrum and the inserted pilot in the signal spectrum are shown in Figure 4 (b) and (c), respectively. The $160 \mathrm{~Gb} / \mathrm{s}$ data and the $10 \mathrm{GHz}$ pilot are transmitted together through a dispersion-managed fiber link consisting of 
$51 \mathrm{~km}$ of standard single-mode fiber (SMF) and a dispersion compensation module (DCM). In the receiver part, the copropagated data and pilot are separated via an optical circulator (OC) and the FBG2. The FBG2 holds an identical central frequency and bandwidth to the FBG1. The data after pilot extraction, in port 2, is shown in Figure 4(d).

The extracted in-band pilot is converted to the electrical domain by a photodiode followed by a transimpedance amplifier whose output is fed to a bandpass filter and then quadrupled $(\times 4)$ to form a $40 \mathrm{GHz}$ clock that drives the EAMbased demultiplexer. Because the pilot and the data are synchronized in the transmitter and are spectrally located close to each other, they are affected by the same fiber impairments leading to the same phase drifts. Therefore, the relative phase difference between clock and data is preserved along the fiber links.
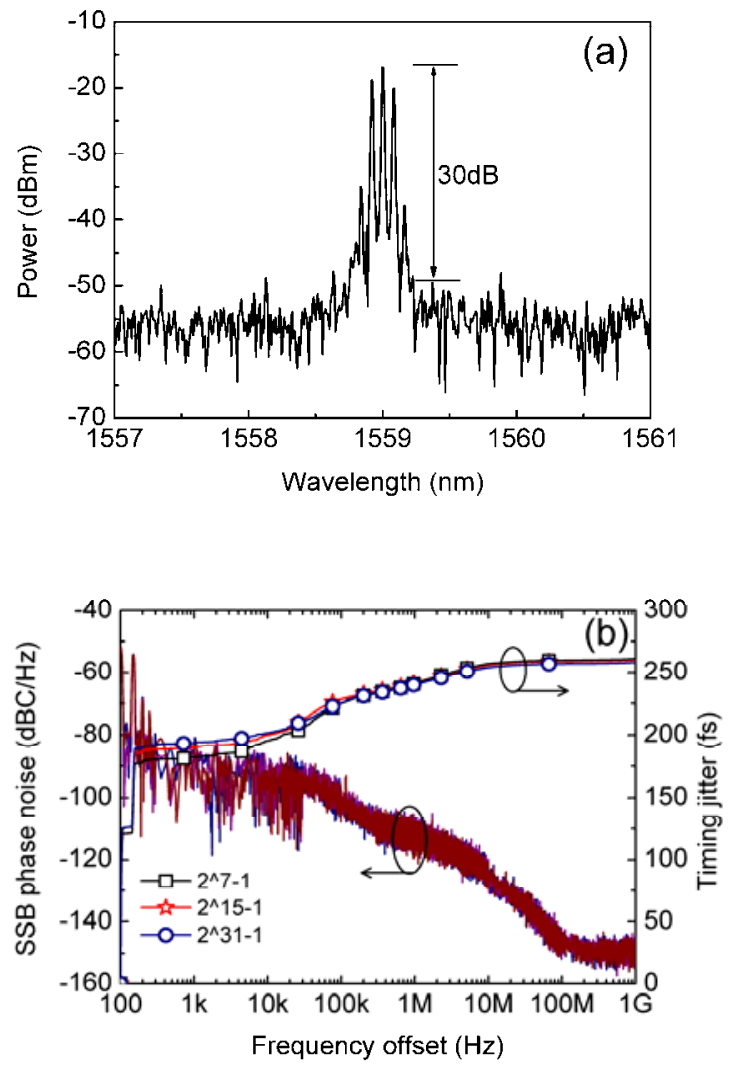

Figure 5. (a) Optical spectrum of the recovered clock, (b) SSB phase noise and timing jitter of the recovered clock after $51 \mathrm{~km}$ fibertransmission for three different PRBS sequences.

In Figure 5(a) we can observe the quality of the recovered clock that holds modulation peaks at $10 \mathrm{GHz}$ with a signal to noise ratio of more than $30 \mathrm{~dB}$. Figure 5(b) illustrates the single sideband (SSB) phase noise and timing jitter estimation of the recovered clock after transmission using three different data patterns: $2^{7}-1,2^{15}-1$ and $2^{31}-1$. For these three pattern lengths we obtained timing jitters of approximately 260 fs using a
$20 \mathrm{MHz}$ electrical filter, proving that the concept is not patternlength dependent.

In order to evaluate the proposed method we use the recovered clock to drive an EAM-based demultiplexer, and carry out BER measurements on the extracted tributaries. The BER performance of the system is described in Figure 6(a). The circles illustrate the 160 -to- $40 \mathrm{~Gb} / \mathrm{s}$ in the back-to-back configuration used as a reference. The squares represent the 160 -to- $40 \mathrm{~Gb} / \mathrm{s}$ before transmission employing the recovered clock, whereas the stars represent the case after transmission. Error-free operation is achieved on all the channels with an average received power of $-11 \mathrm{dBm}$. This value corresponds to an average power penalty of $1.1 \mathrm{~dB}$ between the reference and the case after transmission. This penalty is mainly due to the carving effect of the FBGs on the data signal. In the experiment, we use two $0.4 \mathrm{~nm}(50 \mathrm{GHz})$ bandwidth FBGs. The penalty can be reduced if more narrow FBGs are employed, ideally with $0.16 \mathrm{~nm}(20 \mathrm{GHz})$ bandwidth. We also observe a penalty of 0.1 $\mathrm{dB}$ between the case before transmission and after transmission that indicates excellent dispersion compensation of the fiberspan. The eye diagrams of the extracted channels before and after transmission are also shown in Figure 6(a), demonstrating excellent working of the demultiplexer.
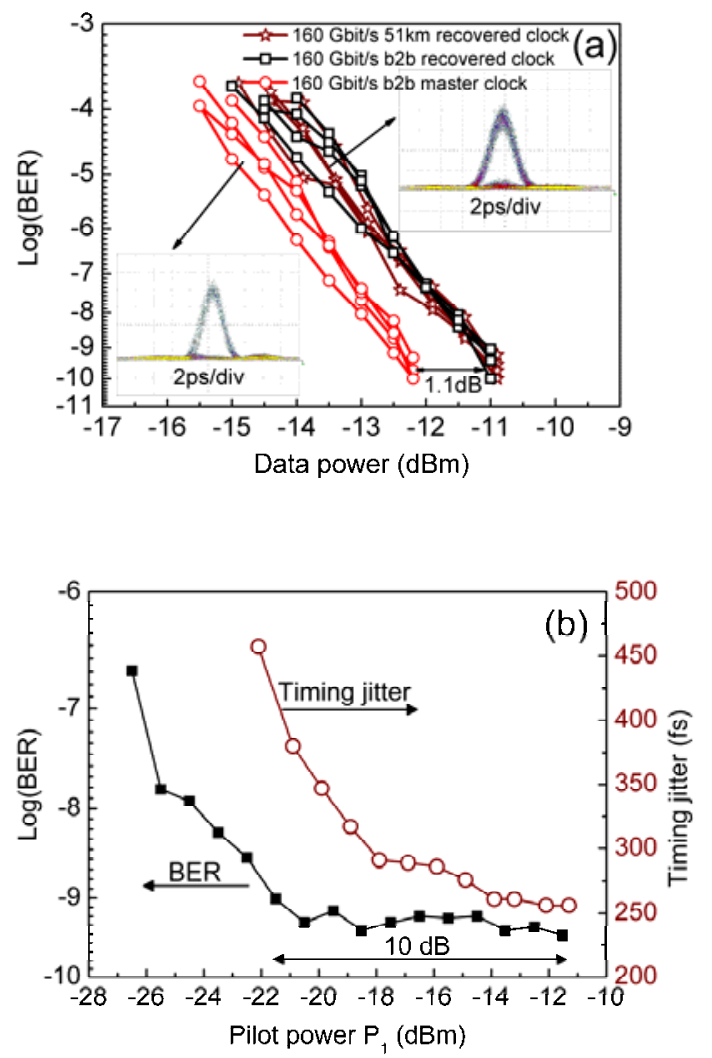

Figure 6. (a) BER curves of the $40 \mathrm{~Gb} / \mathrm{s}$ channels: using the master clock (circles) and the recovered clock before (squares) and after transmission (stars); (b) BER and timing jitter vs pilot power $\mathrm{P}_{1}$. 
The dependence of timing jitter on the optical power of the clock pilot $\mathrm{P}_{1}$ and its effect on the BER is investigated. This so called dynamic range measurement was done by varying the pilot power $\mathrm{P}_{1}$ and by keeping the input power $\mathrm{P}_{2}$ to the clockrecovery unit constant. As shown in Fig. 1, an attenuator (Att1) varies $\mathrm{P}_{1}$ by $14 \mathrm{~dB}$ and a combination of an EDFA and Att2 keeps $\mathrm{P}_{2}$ constant at a certain level for driving the DEMUX and the BERT. As shown on Figure 6(b), if the pilot power decreases by $10 \mathrm{~dB}$, then the timing jitter increases by approximately $200 \mathrm{fs}$. This timing jitter increase will not lead to a dramatic increase of BER values. BER values will sharply increase when the pilot power fluctuates by more than $10 \mathrm{~dB}$. This result is in general similar to the analyses presented in [13]. It is worth to note that when the pilot power is increased above $-14 \mathrm{dBm}$, the timing jitter remains at about $260 \mathrm{fs}$ which is determined by the noise level of the photodiode and electrical amplifiers. However, with the increasing of the pilot power, the residual signal of the pilot after pilot extraction will affect the data signal due to the only $30 \mathrm{~dB}$ suppression of rejection band of the FBGs, so we keep the pilot power close to that of the neighboring $160 \mathrm{GHz}$ peak, which causes a negligible influence on the OTDM data signal and introduces an acceptable timing jitter. The results were obtained using a PRBS pattern of $2^{7}-1$ and can be extended to longer data pattern lengths since this concept is pattern-length independent. During the experiments no loss of clock was observed and the receiver showed stable and repeatable results.

\section{CONCLUSIONS}

We have demonstrated a high-speed optical wavelength converter that is capable of converting the data to the same wavelength using a single SOA. Error-free $40 \mathrm{~Gb} / \mathrm{s}$ operation is demonstrated. The wavelength converter utilizes counterpropagation scheme assisted by blue-detuned optical filtering technology. The blue-detuned optical filtering technology still functions well to dramatically speed up the recovery time of our counter-propagation system. The counter-propagation system shows a slow gain saturation time, which becomes a determinant factor for the operating speed. This wavelength converter has a simple configuration and allows photonic integration. We have also presented a novel self-clocking concept based on inserting at the transmitter and extracting at the receiver a clock pilot which is located in the data spectrum. The clock recovery function is realized by the proposed method, which eliminates the need for an ultrafast phase comparator and a phase locked loop scheme. The concept leads to fast synchronization, low timing jitter and highly stable demultiplexing performance. The proposed method simplifies the design of an OTDM receiver and requires minor modifications of the standard OTDM transmitter.

\section{REFERENCES}

[1] D.J. Blumenthal, J. E. Bowers, L. Rau, H. F. Chou, S. Rangarajan, W. Wang and H. N. Poulsen, "Optical signal processing for optical packet switching networks", IEEE Opt. Comm., S23-S29, 2003

[2] Y. Liu, E. Tangdiongga, Z. Li, S. Zhang, H. d. Waardt, G. D. Khoe and H.J.S. Dorren Liu, Y., et al, 'Error-free $320 \mathrm{~Gb} / \mathrm{s}$ all-optical wavelength conversion using a single semiconductor optical amplifier,' Journal Lightwave Technology, vol. 25, pp. 103-108, Jan. 2007.

[3] Y. Liu, E. Tangdiongga, Z. Li, S. Zhang, H. d. Waardt, G. D. Khoe and H.J.S. Dorren, "Error-free all-optical wavelength conversion at 160 Gbit/s using a semiconductor optical amplifier and an optical bandpass filter," Journal of Lightwave Technology, vol. 24, pp. 230-236, Jan. 2006 .

[4] J. Leuthold, L. Moller, J. Jaques, S. Cabot, L. Zhang, P. Bernasconi, M. Cappuzzo, L. Gomez, E. Laskowski, E. Chen, A. Wong-Foy and A. Griffin, "160 Gbit/s SOA all-optical wavelength converter and assessment of its regenerative properties", Electron. Lett., vol.40, pp. 554-555, 2004.

[5] Jianji Dong, Xinliang Zhang, Songnian Fu, Jing Xu, P. Shum, and Dexiu Huang, "Ultrafast all-optical signal processing based on single semiconductor optical amplifier and optical filtering", IEEE Journal of Selected Topics in Quantum Electronics, vol. 14, pp.770-778, May/June 2008.

[6] R. J. Manning X. Yang, R.P. Webb, R. Giller, F.C. Garcia Gunning, and A.D. Ellis: "The 'Turbo-Switch' - a novel technique to increase the high-speed response of SOAs for wavelength conversion", OFC/NFOEC 2006, OWS8, Anaheim, California, USA, March, 2006.

[7] J.A.Summers, M.L.Masanovic, V.Lal and D.J.Blumenthal, "Design and operation of a monolithically integrated two-stage tunable all-optical wavelength converter," IEEE Photonics Technology Letters, vol.19, pp.1248-1250, 2007.

[8] O. Kamatani and S. Kawanishi, "Ultrahigh-speed clock recovery with phase lock loop based on four-wave mixing in a traveling-wave laser diode amplifier,” J. Lightwave Technol. vol. 14, pp. 1757-1767, 1996.

[9] H. C. Hansen Mulvad, E. Tangdiongga, , H. de Waardt, and H. J. S. Dorren, "40 GHz clock recovery from 640-Gbit/s OTDM signal using SOA-based phase comparator," Electron. Lett., vol. 44, pp.146-148, 2008.

[10] M. Nakazawa, T. Yamamoto, K. R. Tamura, "Utrahigh-speed OTDM transmission beyond 1 Tera bit-per-second using a femtosecond pulse train," IEICE Trans. Electron., vol. E85-C, pp.117-125, 2002.

[11] L.K. Oxenløwe, F. Gomez-Agis, C. Ware, S. Kurimura, H.C.H. Mulvad, M. Galili, H. Nakajima, J. Ichikawa, D. Erasme, A.T. Clausen, and P. Jeppesen, "640-Gbit/s Data Transmission and Clock Recovery Using an Ultrafast Periodically Poled Lithium Niobate Device," J. Lightwave Technol. vol. 27, pp. 205-213, 2009.

[12] C. Boerner, V. Marembert, S. Ferber, C. Schubert, C. SchmidtLanghorst, R. Ludwig, and H.G. Weber, " $320 \mathrm{Gbit} / \mathrm{s}$ clock recovery with electro-optical PLL using a bidirectionally operated electroabsorption modulator as phase comparator," in Optical Fiber Communication Conference, Vol. 2 of 2005 OSA Technical Digest Series (Optical Society of America, 1996), paper 349-351.

[13] Masahiko Jinno, "Effect of timing jitter on an optically controlled picosecond optical switch," Opt. Lett. Vol.18, pp. 1409-1411, 1993. 